\title{
IMPLICAÇÕES DOS INVESTIMENTOS PÚBLICOS E PRIVADOS DE CUNHO TURÍSTICO, IMOBILIÁRIO E INDUSTRIAL SOBRE UMA COMUNIDADE NATIVA NA PERSPECTIVA DE TERRITÓRIO
}

\author{
Rita Rovai Castellan ${ }^{1}$ \\ Débora Coutinho Paschoal Dourado \\ Diego Costa Mendes ${ }^{3}$
}

Resumo: A historicidade de um território é escrita pela totalidade social e dinâmica das transformações da sociedade (SANTOS, 2002). Esse artigo procura descrever e analisar as transformações no território da Região da Praia do Paiva, com esse olhar. Foram realizadas entrevistas balizadas na história oral (ALBERTI, 2011; THOMPSON, 1992) e analisadas através da análise cruzada (THOMPSON, 1992). Nos resultados, as transformações na Região da Praia do Paiva são pontuadas por vantagens marcantes para o capital econômico de cunho turístico, imobiliário e industrial, impossibilitando a construção de uma história das ações que seja diferente do projeto dos atores hegemônicos, conforme sugere Santos (2002).

Palavras-Chave: Território; Investimentos Públicos e Privados; Comunidade.

\section{IMPLICATIONS OF PUBLIC AND PRIVATE INVESTMENTS \\ ARISING OUT OF SECTORS TOURISM, REAL ESTATE AND INDUSTRIAL ON A NATIVE COMMUNITY PLANNING IN PERSPECTIVE OF THE TERRITORY}

\begin{abstract}
The historicity of a territory is written by the social totality and dynamic of society transformation (SANTOS, 2002). This article aims to describe and analyze the changes in the Region of Praia do Paiva territory, with that look. Interviews were conducted deliniated in oral history (ALBERTI, 2011; THOMPSON, 1992) and analyzed by cross-analysis (Thompson, 1992). In the results, transformations in the Region of Praia do Paiva are punctuated by remarkable advantages for the economic capital for tourism, real estate market and industry, precluding the construction of a history of actions different of the hegemonic actors project, as suggested by Santos (2002).
\end{abstract}

Keyworks: Territory; Private and Public Investments; Community.

\section{INTRODUÇÃO}

Todo território tem uma história que provém não só de um conjunto de sistemas naturais, mas também dos acréscimos impostos pelo homem, por meio de um domínio ou de uma delimitação do vivido territorial, que assume múltiplas formas e determinações (SANTOS,

\footnotetext{
${ }^{1}$ Profa. Ms. do Instituto Federal de Pernambuco. E-mail: ritarovai@gmail.com

${ }^{2}$ Prof. Dra. do Programa de Pós-Graduação em Administração (PROPAD) da UFPE. E-mail: dcpdourado@gmail.com

${ }^{3}$ Mestrando em Administração pelo Programa de Pós-Graduação em Administração (PROPAD) da UFPE. E-mail: diegocostape@gmail.com DOI: 10.7154/RDG.2013.0025.0012
} 
2002). Historicidade escrita pelas transformações geradas pela dinâmica da própria sociedade e marcada por lutas de comunidades nativas na defesa desses territórios.

Essas lutas têm como elementos a desigualdade de forças, de poder político, social e cultural; fazem parte do processo histórico civilizatório, e emergem quando novos agentes chegam a um território, já habitado, apropriado por uma comunidade nativa e que, por razões diversas, visualizam para aquele território novos horizontes, uma nova lógica de trabalho (LITTLE, 2002).

Nesse sentido, o estabelecimento de mega empreendimentos, de cunho industrial, logístico, turístico, imobiliário ou rodoviário, quando incorporados a um território por novos agentes causam grandes alterações econômicas, sócioambientais e culturais e determinam ciclos de transformações na história desse território.

Infere-se aqui que essas intervenções regulamentam os diversos interesses de poder e de classe e estabelecem estratégias sociais e políticas, geradoras de segregações e exclusões sociais dos antigos moradores (PESSOA; BÓGUS, 2008). Dessa forma, os investimentos privados e públicos, sob o ponto de vista social estimulam transformações no território e no seu significado gerando um conjunto próprio de choques territoriais e, com isso, ondas de territorialização (LITTLE, 2002).

Exemplos dessas intervenções territoriais estão presentes em todo território nacional, principalmente na costa litorânea, pela sua posição estratégica diante dos mercados europeus e por suas praias paradisíacas.

No litoral sul do Estado de Pernambuco, nomeadamente na Região da Praia do Paiva, observam-se exemplos dessas transformações. Desde o inicio da década de 70, vindo em um crescente, grandes empreendimentos turísticos, imobiliários e industriais estão se instalando na região e alterando a vida da comunidade local, tornando a competitividade uma regra de convivência, e os territórios, mediante suas potencialidades, transformam-se em palco de disputas entre as grandes corporações (SANTOS, 2001). Corporações que contam com o apoio de Instituições Governamentais e são apresentadas como "salvadores dos lugares, credores de reconhecimento pelos seus aportes de emprego e modernidade" (SANTOS, 2001, p. 34).

Apesar desse discurso, essas intervenções territoriais mostram que a relação de identidade com o território dos antigos moradores difere completamente do sentido dado, a esse mesmo território, por parte dos novos habitantes. 
Assim, com a intenção de entender o contexto descrito acima, surge a proposta desse artigo: descrever e analisar, sob uma perspectiva histórica, as transformações territoriais na Região da Praia do Paiva - PE. Para isso, iniciamos apresentando o conceito território na visão de Santos $(1996,1999,2002,2001)$, suporte teórico desse estudo. Na sequência, descrevemos a metodologia adotada. Finalizamos com a descrição das transformações na Região da Praia do Paiva, sua análise a partir do referencial de território, e nossas conclusões.

\section{Compreendendo Território}

O conceito território é complexo, substantivado por vários elementos e estudado por diversos autores, cada um com um enfoque centrado em uma determinada visão em função dos recortes e das problemáticas que pretende responder (FERNANDES, 2009). Neste estudo, o conceito território será balizado pela perspectiva de Santos (1996, 1999, 2002, 2001).

Olhar para um território, na visão de Milton Santos significa procurar entender a totalidade social e dinâmica das transformações da sociedade. É por meio da interdependência e a inseparabilidade dos recursos presentes na sociedade que os homens mudam seu território e a si próprios. A existência separada de cada recurso não determina seu valor real, mas sim, o fato de estarem inseridos de forma conjunta em um determinado território.

Cada recurso, dessa forma, é uma manifestação do fenômeno social total e seu valor efetivo é dado pelo território em que se manifesta (SANTOS, 2001). Por recursos o autor compreende os indivíduos, empresas, instituições, governo, elementos naturais e artificiais, ideias, sentimentos, valores, os quais precisam ser considerados sempre de forma conjunta. Esses recursos se renovam, criando, assim, outra totalidade a partir das transformações que marcam cada momento histórico, cuja determinação se dá a partir das necessidades sociais, econômicas e políticas que se diferenciam por meio de formas, dos mecanismos, das técnicas de produção (SANTOS, 1996).

Para o autor o uso e o controle social do território, a partir das ações dos indivíduos, é o fator gerador de mudanças na configuração territorial, tornando-a hibrida e historicamente mutável. O território, dessa forma passa a ser, o produto das ações de diversos atores que partem de uma realidade material dada e que de uma forma concreta ou abstrata "territorializam" esse espaço (Raffestin, 1993). 
As grandes organizações, um desses atores, utilizam-se de seu poder econômico e usam o território como um recurso que garanta a realização de seus interesses. Essa lógica nos mostra que a maior produtividade procurada pelas grandes corporações deixa de ser definida apenas pela estrutura interna da empresa e passa também a considerar os atributos do território (SANTOS, 1999).

Assim, infere-se que as potencialidades de um território são fatores determinantes quando da escolha de um lugar onde se estabelecer. As grandes corporações transnacionais, a partir do processo de globalização dos recursos financeiros, dos produtos e serviços, buscam sempre territórios, cujas potencialidades lhe permitam obter maiores lucros (SANTOS, 1999).

Nesta compreensão, a definição de território considera a interdependência e a inseparabilidade entre a materialidade, que inclui a natureza, e o seu uso; assim como a ação humana, isto é, o trabalho e a política (SANTOS; SILVEIRA, 2008).

A partir de uma relação dialética entre a natureza (objeto), o trabalho e a política (ações), Santos (2002) sugere novos recortes no território decorrente do processo de globalização, que ganham funcionalidades a partir das redes. Para ele, é por meio das redes que se pode falar das horizontalidades e verticalidades do espaço, que são arranjos espaciais de pontos descontínuos, mas interligados entre os recursos.

As horizontalidades estão relacionadas a territórios próximos, "extensões formadas de pontos que se agregam sem descontinuidade" (SANTOS, 2002, p. 284). São caracterizadas "tanto pelas articulações, quanto pelos benefícios gerados no âmbito local, pelas ações de um determinado ator sobre o território onde se instala" (GOULART, 2010, p. 397). Geram forças centrípetas, resultantes do processo econômico-social.

As verticalidades, por sua vez, são "pontos que separados uns dos outros asseguram o funcionamento global da sociedade e da economia, criando interdependências quanto maiores sejam as necessidades de cooperação entre os territórios" (SANTOS, 2002, p. 191). Essas interdependências são hierarquizadas mediante ordens técnicas, financeiras e políticas, sobretudo, a serviço de forças econômicas hegemônicas e a serviço do Estado, que é o grande regedor das ações que definem as novas realidades espaciais (SANTOS, 2002). Para Santos (2002), o contexto globalizado maximiza as possibilidades das verticalidades dos territórios, porém, os territórios podem, por sua vez, fortalecer suas horizontalidades 
mediante "ações localmente constituídas, uma base de vida que amplie a coesão da sociedade civil, a serviço do interesse coletivo" (p.194).

A historicidade da dialética entre as horizontalidades e verticalidades dos territórios aponta para mais impactos negativos do que positivos. A descaracterização, e consequente perca da identidade do local (SOUZA NETO et al, 2008); o desprezo à economia local e alteração da estrutura espacial, assim como a degradação do meio ambiente (SIMÕES, 2009); o turismo como uma prática social de apropriação e de dominação de muitos territórios (CORIOLANO, 2006); a redefinição da identidade étnica e política a partir das fronteiras que se demarcam nas relações travadas com os responsáveis pelo empreendimento (ARAUJO; BELO, 2009) são alguns temas investigados apesar da especificidade de cada estudo.

Assim, as grandes corporações ao estabelecerem as regras em suas relações verticais e horizontais induzem a uma determinada divisão do trabalho que atendam a seus próprios interesses, inferindo-se que o uso de recursos públicos destinados a infraestrutura em benefícios das grandes corporações nacionais, transnacionais sobrepõe o atendimento de problemas sociais e locais (SANTOS, 2002).

Segundo Santos (2002), na disputa pelo uso do espaço, as empresas ficam em uma situação privilegiada em relação às comunidades locais, ao considerarmos a relação desigual de poder. De acordo com o autor, mais do que a formação socioeconômica é a formação sócioespacial que exerce o papel de mediação entre o mundo e o território, ou melhor, as diversas formas de se utilizar esse território.

\section{MATERIAIS E MÉTODOS}

Esse estudo pode ser caracterizado pelo tipo descritivo-analítico (TRIVIÑOS, 2006). O lócus da pesquisa foi delimitado em um contínuo, considerando as transformações territoriais da região, indo da Praia do Paiva, no município do Cabo de Santo Agostinho, até o Complexo Industrial Portuário de Suape, no município de Ipojuca. Salienta-se que os dois municípios possuem um cenário de praias paradisíacas, e uma localização estratégica privilegiada, atraindo, dessa forma, investimentos de grande porte, cuja implantação altera sua realidade territorial, sua técnica de produção e a vida de seus moradores.

Para a coleta de dados optou-se pelo método biográfico (GOLDENBERG, 2000, p. 36). Dentre as possibilidades apresentadas pelos estudos biográficos, optou-se pela técnica da história 
oral, e para sua operacionalização pela entrevista de historia de vida (ALBERTI, 2011) com os pescadores artesanais da região, por meio de uma amostragem não probabilística intencional (MARCONI; LAKATOS, 1999). Estipulou-se apenas um critério: o entrevistado teria que exercer a atividade da pesca artesanal na extensão da Região da Praia do Paiva. Foram realizadas 17 entrevistas (11 homens e 6 mulheres). Cada entrevista durou em torno de 30 a 40 minutos, na qual o pescador relatou sua infância com relação à pesca e as transformações em função das mudanças que ocorreram e estão ocorrendo em seu território.

No sentido de complementar as informações coletadas, a partir da história oral, foi utilizada a observação não participante (MERRIAM, 1998). Outro instrumento usado para complementar as entrevistas realizadas foi a pesquisa documental (FLICK, 2009), através de uma vasta pesquisa na internet sobre a região, nomeadamente sobre os Municípios do Cabo de Santo Agostinho e Ipojuca, assim como os sites oficiais sobre os empreendimentos turísticos, imobiliários e industriais de grande porte que estão se instalando na Região da Praia do Paiva.

O processo de análise dos dados foi realizado por meio da análise cruzada sugerida por Thompson (2002). À medida que se construíram as análises, contrapondo as evidências coletadas por todos os instrumentos usados (entrevistas, observação não participante e pesquisa documental), tomou-se o cuidado, sugerido por Thompson (2002), em não atribuir às palavras dos entrevistados significados que os mesmos recusariam.

\section{RESULTADOS}

De acordo com a pesquisa de campo, foram quatro os fatores impulsionadores das mudanças, nesse território, que impactaram na região como um todo. Primeiro, a construção do Porto de Suape, fundado em 7 de novembro de 1978, por meio de uma lei estadual n. 7.763, que criou a empresa Suape Complexo Industrial Portuário para administrar o desenvolvimento das obras.

Segundo, a construção em 1986, do Hotel Vila Galé Eco-Resort do Cabo, na Praia de Suape. Terceiro, em 1986, as vendas de lotes do primeiro bairro planejado do Recife, na Praia do Paiva. Loteamento cujas vendas permaneceram abertas apenas por alguns meses. Em 2007, as vendas retornaram sob um novo conceito, o Complexo de Turismo e Lazer da Praia do Paiva, condomínio destinado ao mercado de alto luxo. 
A quarta intervenção na RPP refere-se às obras de infraestrutura de acesso ao Complexo de Turismo e Lazer da Praia do Paiva, a Via Parque, e a Ponte sobre o Rio Jaboatão, com o apoio do Governo Estadual, por meio da primeira Parceria Pública Privada do Estado.

$\mathrm{Na}$ sequência, apresentamos o detalhamento das transformações territoriais da região pesquisada.

\section{Complexo Industrial Portuário de Suape antes e depois}

Cronologicamente, a primeira intervenção identificada no território estudado foi a implantação do Complexo Industrial-Portuário de Suape, no Cabo de Santo Agostinho, em 1978, por meio de um Plano Diretor, do então Governo do Estado de Pernambuco.

A localização escolhida para o empreendimento, devido às suas potencialidades estratégicas, abrange uma parte do continente litorâneo, pertencente aos municípios de Ipojuca e do Cabo de Santo Agostinho, a ilha de Tatuoca e a ilha de Cocaia. Esta última, nunca foi habitada e desde o início das obras do porto foi interditada. Já na llha de Tatuoca existe uma comunidade de pescadores, composta de 59 famílias, que sobrevive da pesca artesanal. Essa comunidade foi a primeira a sentir os impactos do novo empreendimento.

$\mathrm{O}$ aterro dos manguezais que separavam a ilha do continente permitiu o acesso por carro, por uma estrada de terra, até a vila de pescadores, favorecendo o acesso de "estrangeiros" ao local, alterando a dinâmica social da comunidade.

A implantação do empreendimento gerou também modificações significativas, com desapropriações de inúmeras propriedades, terras de antigos engenhos (Tiriri, Godoais, dentre outros), assim como de terras próximas, que vão desde a Praia de Suape, no município do Cabo de Santo Agostinho, até o município de Ipojuca.

Entre 1989 e 1992, a ampliação do Complexo Portuário, objetivando receber supercargueiros, aprofundou e alargou o curso do Rio Ipojuca. Essa ação provocou o desmatamento de mais de 500 hectares de mangue, inviabilizando, praticamente, a pesca realizada nos estuários e em todo mar-de-dentro (pesca antes dos arrecifes) na região suapense.

Desde então, percebe-se um crescimento exponencial de indústrias nas adjacências do empreendimento. De 2007 a 2010, foram realizados investimentos na ordem de US\$17 bilhões, em especial, na implantação de empreendimentos estruturadores e outras 
iniciativas de grande porte, oriundas do Governo Federal, em áreas conexas do Porto de Suape (SAMPAIO, 2011).

A Refinaria Abreu e Lima, por meio de uma parceria com o governo Venezuelano e o Estado de Pernambuco, e o Estaleiro Atlântico Sul são exemplos de investimentos realizados na região. Por sua vez, estes investimentos resultaram em novas intervenções no território, atraídos pelas potencialidades econômicas que o lugar passou a apresentar.

As potencialidades desses empreendimentos são exaltadas pela mídia, concedendo à região o status de "oásis econômico", conforme se exemplifica abaixo:

O Porto de Suape detém hoje um conjunto de vantagens competitivas para sediar um importante polo de empresas da cadeia de petróleo, gás, offshore e naval e a presença de uma refinaria de petróleo e de vários estaleiros atestam este potencial afirma Tania Bacelar, economista Suape é a jóia da coroa pernambucana. Uma maravilha logística. Uma poupança do povo de Pernambuco feita por mais de 30 anos, sem interrupção e no lugar certo, na visão de Francisco Cunha, empresário (SAMPAIO, 2011).

Observa-se que a implantação desses empreendimentos formata um novo território e novas territorialidades são construídas, resultantes das interações entre dois agentes principais desse processo: os antigos moradores e os investidores. Interações que estão, como toda e qualquer relação social, inseridas em um campo de poder. Percebe-se que esses dois agentes fazem uso de instrumentos de poder presentes na sociedade em graus diversos, em momentos diferentes e em lugares variados, tornando suas relações de poder um componente indispensável na efetivação desse novo território.

Configura-se aqui uma relação de poder hierarquizada, construída a partir da necessidade de interação entre os antigos moradores e os outros elos da comunidade (governo, comércio, outras comunidades, empresas, etc.), que se materializam a partir dos seus efeitos (RAFFESTIN, 1993).

A fala dos pescadores E.A.S. (R6) e H.P. (R3) ilustram esta relação (R6).

[...] Manda quem pode, obedece quem tem juízo... e ele vai dizer que não pode?... mermo que teja errado, mas ele vai dizer que tá certo. Meu irmão foi preso por causa de 2 varas que tirou pra remar... 2 varas... preso não, detido... que no mermo dia foi solto... No mermo canto que o meu irmão tirou as 2 varas, você chega lá hoje meteram a máquina moto cerra pra cima, toraram meio mundo de mata, pra passar um cano da refinaria... aí... agora... cadê o documento do CPRH ou IBAMA?... tá tudo autorizado... é isso (E.A.S., R6).

[...] A gente não pode tirar uma madeira do mangue pra fazer um corvo... mas, quando o estaleiro quer desmatar o mangue pode... eu não sei que lei 
é essa, né? O IBAMA, autorizando e não vê isso... Se eles pegar a gente com galho de madeira... (um...) Vai preso! (H.P, R3).

A história da implantação do Complexo Industrial Portuário de Suape é, necessariamente, uma história territorial, já que a expansão desse agente social, com sua própria conduta territorial, entra em choque com as territorialidades dos antigos moradores que ali residiam. As fotos seguintes mostram o antes e o depois das intervenções.

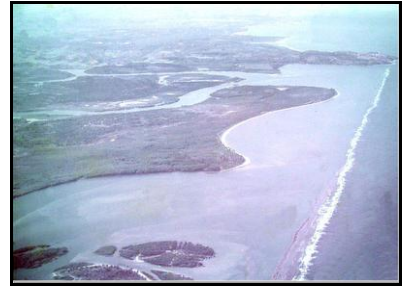

Figura 1

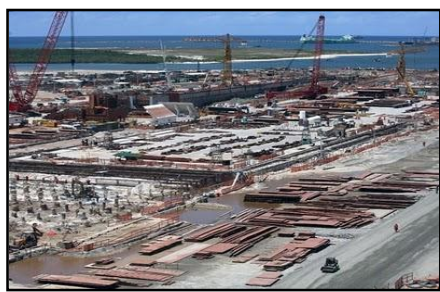

Figura 2

Figura 1 e 2 - Área de Suape, antes e depois do Complexo Industrial Portuário de Suape Fonte: www.suape.gov.br

A segunda intervenção geradora de transformações foi a construção do Hotel Vila Galé EcoResort do Cabo, descrita a seguir.

\section{Hotel Vila Galé Eco-Resort do Cabo}

A $50 \mathrm{~km}$ do Recife, no município de Cabo de Santo Agostinho, a praia de Suape se destaca por sua paisagem natural, composta de mangues, estuários, vegetação remanescente da Mata Atlântica, e por estar cercada pelos rios Massanganda e Ipojuca e banhada pelo Oceano Atlântico.

Neste paraíso, foi construído, em 1986, o Hotel Vila Galé Eco-Resort do Cabo, cumprindo as determinações da Associação Brasileira de Resort. Segundo esta Associação, é considerado "um resort" o empreendimento que for destino exclusivo e diferenciado, assim como o que for dotado de excelente infraestrutura e situado num local paradisíaco (BYDLOWSKI, 2002 apud RAMALHO, 2007).

Os investidores do empreendimento turístico, a empresa pernambucana Ipojuca Empreendimentos e Participações S/A, o grupo Japonês AOKI (dono da rede mundial Ceasar Park) e o FUNCEF (Fundo de Pensão dos Funcionários da Caixa Econômica Federal), escolheram o local certo (OLIVEIRA, 1997 apud RAMALHO, 2007).

A área foi escolhida em função da disponibilidade e garantia de recursos necessários à reprodução material do grupo de investidores (HAESBAERT, 2004). Com a construção do Resort, a orla da praia de Suape, até então ocupada pelos barcos, redes e casas dos 
pescadores artesanais, cede lugar aos turistas estrangeiros, de alto poder aquisitivo, públicoalvo deste tipo de turismo, e altera o jeito de viver dos seus antigos moradores. Com isso, as chegadas e saídas dos barcos para o mar, as conversas dos pescadores, quando da espera para retirar as redes, as histórias e seus mitos, tiveram que se adaptar às novas formas de comportamento e aos valores trazidos por esses novos agentes do território.

O relato do pescador M.A. (R15) apresenta uma dimensão desse problema:

[...] Tinham mais ou menos 25 homens trabalhando para desmatar o mangue. [...] mas tinha hora que eu chorava, eu via os caranguejos, tinha o mangue e tinha a mata né [...]. E quando foram o desmatamento dos mangue os caranguejos saia de bando pra mata, coitados, que não tinha pra onde ir [...] (M.A., R15).

Percebe-se, ainda, que apesar das inúmeras intervenções dos Órgãos Governamentais, acompanhadas pela mídia e por diversas Organizações Não Governamentais (ONG) relacionadas ao meio ambiente, a obra terminou, conforme o planejado, mostrando-se infrutíferas às reivindicações.

A fala do pescador M.A. (R15) relata isso:

[...] o IBAMA chegou aí, chegou o $\mathrm{CPRH},[. .$.$] não sei o quê mais, repórter,$ mas só que a obra passou três anos embargada, três anos, agora tá feito o hotel, mas acabou-se tudo o mangue... (M.A., R15)

[...] veio o pessoal do jornal, da ONG e da Associação até que brigaram, mas eles tinham o dinheiro né, a taí o hotel [...] (M.A., R15)

Nessa segunda intervenção do território da RPP, a história se repete. Novos agentes chegam a um território, já apropriado por antigos moradores, e por razões de cunho econômico visualizam para ele novos horizontes (LITTLE, 2002) em detrimento da forma de viver e produzir dos seus antigos moradores.

As fotos abaixo mostram o antes e o depois dessas intervenções:

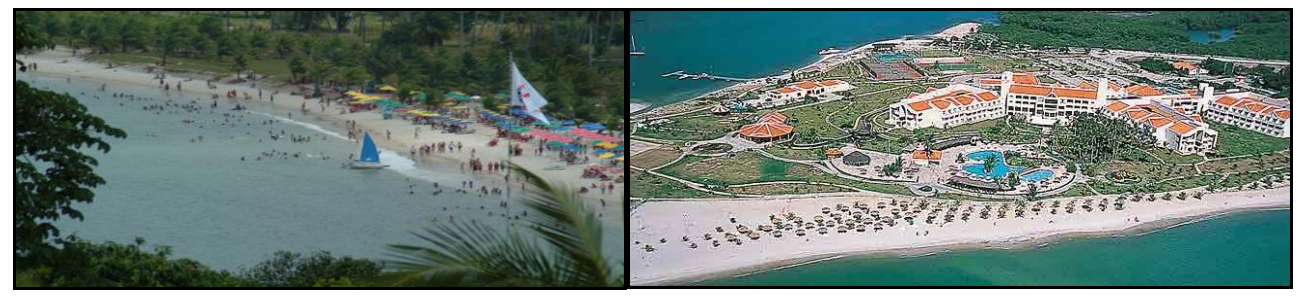

Figura 3

Figura 4

Praia de Suape antes e depois do Hotel Vila Galé Eco-Resort do Cabo Fonte: viagenseturismo.tur.br

A terceira e a quarta intervenção territorial na RPP, que completam a história das transformações no território da Região da Praia do Paiva, foram a construção do Complexo 
de Turismo e Lazer da Praia do Paiva e a infraestrutura de acesso a ele, a Via Parque e a Ponte sobre o rio Jaboatão, descrita na sequência.

\section{Complexo de Turismo e Lazer da Praia do Paiva}

Situada em uma reserva ecológica, no município de Cabo de Santo Agostinho, a $41 \mathrm{~km}$ do Recife, está a Praia do Paiva. Sua história é relativamente obscura. Faltam registros históricos oficiais. Sabe-se que existia ali um grande engenho, onde residiam várias famílias. Muitas destas sobreviviam da atividade pesqueira, no rio Jaboatão, nos mangues da redondeza ou, ainda, no mar-de-fora ou mar-de-dentro (antes ou depois dos arrecifes).

No fim dos anos 70 e início dos anos 80, a família Brennand, mediante pagamento de indenizações, desapropriou as famílias nativas, dentre elas pescadores, e a área foi utilizada para uma plantação de coqueiros, que permanecem nos espaços ainda não ocupados. As pessoas que ali residiam, a maioria pescadores nativos, se transferiram para Pontes dos Carvalhos, região industrial mais próxima. Com a mudança, novos conteúdos e comportamentos foram cobrados desses pescadores devido à nova dinâmica social que se apresentou.

O sentimento de pertencimento a um território, construído por meio do uso comum de uma mesma técnica (SANTOS, 2002), aqui a pesca artesanal, começa a ser desfeito. Apesar de continuarem pescando, a distância física do seu lugar de trabalho - os estuários, o mangue ou o mar - assim como a proximidade da área industrial, vão, aos poucos, alterando o viver desses pescadores.

Em 1986, a família Brennand lançou um projeto de Loteamento da Praia do Paiva como o primeiro bairro planejado do grande Recife, cujas vendas permaneceram apenas por alguns meses. Em 18 de outubro de 2007, um novo empreendimento foi lançado para a Praia do Paiva, mediante iniciativa da Odebrecht e dos Grupos Cornélio e Ricardo Brennand, em parceria com o Governo do Estado. Tratava-se do desenvolvimento e implantação de um destino internacional de turismo e lazer, associado à empreendimentos residenciais e de comércio e serviços de alto padrão, o Complexo de Turismo de Lazer da Praia do Paiva.

Por meio de um discurso propagandístico e com o aval do Governo do Estado, reproduzido abaixo, o empreendimento foi apresentado como "salvador do lugar, credor de reconhecimento pelos seus aportes de empregos e modernidade" (SANTOS, 2001, p. 68). 
O complexo turístico é interessante para o Cabo pelo papel alavancador que terá por meio da geração de empregos, renda e receitas tributárias, decorrentes de atividades econômicas que serão desenvolvidas, além do expressivo impacto social pelo treinamento profissional e capacitação de pessoas, contribuindo para o desenvolvimento da região. "O projeto do Paiva será um empreendimento que marcará a época do desenvolvimento econômico do nosso estado. Vamos reestruturar o destino turístico do nordeste, em particular o de Pernambuco", afirmou Eduardo Campos (SAMPAIO, 2011).

A segunda etapa do empreendimento, que integra três privês, a construção de hotéis cinco estrelas, centro empresarial e de convenções, e um shopping, foi anunciada com o mesmo entusiasmo pela mídia local, conforme abaixo.

O empreendimento está na primeira de três etapas previstas para a obra. No total, o projeto deverá gerar 5.980 postos de trabalho diretos e indiretos apenas no período de construção. Para a operação dos equipamentos, a previsão é que outras 7.025 vagas sejam criadas (Diário de PE, 23/05/2001- Elian Balbino).

Esse discurso, vinculado principalmente à capacitação dos nativos para atender à demanda das atividades econômicas desenvolvidas com a implantação desses investimentos, foi fonte de mudanças significativas no território e na vida dos moradores locais, acarretando, para a sociedade como um todo, um pesado processo de desequilíbrio (SANTOS, 2001). Tais mudanças tiveram o apoio do Governo Federal, por meio de obras estruturadoras e de acesso, conforme descrição na sequência.

\section{Ponte do Paiva e Via Parque}

A ponte do Paiva, de 320 metros, e a estrada Via Parque, com 6,2 km de extensão formaram um sistema viário responsável por ligar Barra de Jangada, no município de Jaboatão dos Guararapes, à Praia do Paiva, no Cabo de Santo Agostinho. Estes dois empreendimentos foram construídos sob o primeiro regime de Parceira Público-Privada entre o Estado de Pernambuco e as Empresa Odebrecht, o Grupo Ricardo Brennand e o Grupo Cornélio Brennand.

Dentre as regras desta parceira, consta a autorização da Odebrecht e do Grupo Cornélio Brennand, por meio de uma empresa subsidiária, para operar um pedágio por um período de 30 anos na Ponte do Paiva. As praças de pedágio estão localizadas no começo e no fim da Reserva do Paiva.

O comentário do Sr. Eduardo Melo (conversa informal - NOTA DE CAMPO 19/05/2012) apresenta outra perspectiva sobre o Projeto: 
[...] ai vieram agora com esse novo projeto modificando o anterior. Que o anterior, a gente já tinha a ponte de forma gratuita, por que era beneficio da propriedade deles. Mas aí com o tempo eles conseguiram essa PPP e isolaram a praia, porque do município de Jaboatão pra lá você tem que pagar e do município do Cabo pra lá você tem que pagar então a Praia do Paiva ficou uma ilha onde você tem que pagar para ter acesso, tanto faz ser morador de Jaboatão como faz morador do Cabo, independente do uso da ponte. (EDUARDO MELO, conversa informal - DIÁRIO DE CAMPO, 19/05/2012).

As fotos abaixo mostram a Praia do Paiva antes e depois da construção da Ponte do Paiva e da Via Parque.

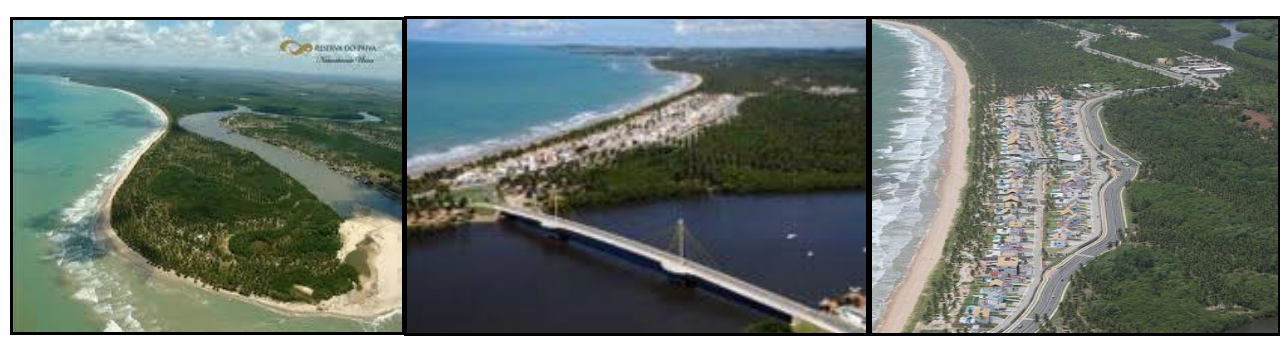

Figura 5
Figura 7

Praia do Paiva antes e depois da Ponte do Paiva, e da Via Parque

Fonte: skyscrapercity.com

Os empreendimentos, aqui citados como geradores das transformações no território da Região da Praia do Paiva contaram com o aval do poder público. Os localizados no extremo sul receberam incentivos fiscais com reduções de $75 \%$ nos impostos federais (SUDENE), e de até $50 \%$ nos municipais. Foram beneficiados também com a possibilidade de participarem de programas estaduais, como o Programa de Desenvolvimento da Indústria Naval e de Mecânica Pesada Associada do Estado de Pernambuco (PRODINPE) e o Programa de Desenvolvimento de Pernambuco (PRODEPE), além da liberação de licenças ambientais das áreas pré-aprovadas (EIA /Rima). Estas informações foram adquiridas no site oficial do Governo do Estado (SAMPAIO, 2011).

\section{Discussão}

O território da Região da Praia do Paiva passa por um dinâmico e complexo processo de transformação, desde meados da década de 70. Transformações que foram determinadas, na sua gênese, por necessidades econômicas e políticas de um grupo de investidores, e que, com o passar do tempo, foram se renovando, criando outras totalidades para o território, que, no futuro, poderão até demarcar momentos históricos da região (SANTOS, 1996, 2002). 
A história dessas transformações demonstra uma disputa pelo uso de um mesmo espaço, onde os empreendimentos estão em uma situação privilegiada, com relação à comunidade local.

A chegada de novos moradores alterou a forma de viver do local, tanto para os pescadores como para seus outros moradores. As reclamações, como a falta de segurança, o aumento do custo de vida e a perda da tranquilidade do local, passaram a ser uma constante, na fala do povo nativo. Um dos pescadores entrevistados, M.A. (R15) comenta sobre os novos habitantes do local:

[...] têm os nativos, que nasceram aqui, têm os locais que vieram morar aqui, mas que cuidam daqui e têm os invasores, são os que vieram trabalhar no porto e não cuidam daqui (M.A, R15).

A força da palavra "invasora", utilizada pelo pescador M.A. (R15), denota o choque de valores presentes entre os atuais moradores da Região da Praia do Paiva e a população nativa.

Outro fator marcante de transformação territorial foram os aterros realizados para a construção dos três empreendimentos da Região. As marisqueiras foram as mais prejudicadas, uma vez que suas atividades dependiam do ambiente de mangue (RAMALHO, 2007). Porém, os impactos também foram percebidos em outros pontos da Região da Praia do Paiva. A fala do pescador R.V.A. (R12), da Praia do Paiva, ilustra isso:

[...] lá em Suape mesmo, a pescaria de estuário acabou, por conta da draga da Petrobrás e aqui é essa água barrenta como você esta vendo [se referindo a Praia do Paiva] que prejudica a pesca (R.V.A, R12) (grifo dos autores).

Do mesmo modo, é ilustrado pela fala do pescador M.A. (R15), quando explica o que está acontecendo na Praia de Suape, ou ainda a do pescador N.M. (R16), quando desabafa, em tom irônico, e deixa transparecer um sentimento de revolta sobre essas ações no ambiente natural:

[...] Olha esse navio pequeno, mais próximo aí é uma draga navio, [apontando para um navio] estão tirando material ai. Tem outra draga lá na frente [...] tão fazendo um canal pra chegar navio grande petroleiro para a Refinaria, tão para inaugurar dois piers, está desativado ainda, aí, a pesca vai diminuir né, vai acabar (M.A, R15).

[...] Essa barra aqui é natural, [aponta para o lado direito da praia] a de lá é artificial. Explodiram ali o arrecife, dinamitaram, tiraram 300 metros. Antes a gente pescava lá, agora, acabou (M.A, R15). 
[...] Do jeito que eles estão querendo a gente, vamos ter que colocar água no barco para passar, por aqui é a barra (apontando para o lado direito da praia), aqui no inverno a gente não passa, a gente só passa lá, (apontando para o lado esquerdo da praia, próximo ao porto) se eles tapar (sic) como é que o cabra vai passar, vai ter que colocar água no barco (N.M., R16).

O pescador J.E.S. (R1) complementa tais argumentos:

[...] É, do jeito que tá, num vai demorar muito não, o governo tá acabando com a tradição da pescaria, e num é só daqui, é exatamente, é o que eu estou dizendo. Cada vez aumenta mais, vai se distanciando. Tatuoca eles já acabaram com as marisqueira (J.E.S., R1).

Os comentários dos pescadores da RPP sobre as ações que mudaram seu território continuam. Os pescadores A.M.F. (R4)e o pescador R.V.A. (R16) tecem mais comentários:

[...] Tudo. Mudou tudo, através desse Porto de Suape. Tudo. O peixe diminuiu, Marisquinho diminuiu, teve um tempo que Marisquinho não tinha aí, tinha que ir pra Mangue Seco, tá entendendo?... Tinha que ir ali pro lado de Itamaracá, porque aqui não tava dando. A Draga tava prejudicando tudo, Tá entendendo?... Aí tudo ficou difícil (A.M.F., R4).

[...] Não, logo assim, não houve, logo assim, não deu tanto pra você notar, Agora, depois que começou as dragagens, e agora que aumentaram, isso aí depois de 5 anos pra cá. Pronto. Aí saiu, tudo vai mudando, eu tenho pra mim também que quando vai chegando um tempo, tudo vai acabar, toda a pesca por aqui (R.V.A. R16)

Percebe-se que a draga (maquinário utilizado pela Petrobrás), símbolo de destruição do território, tem um significado diferente para os donos do capital e para o governo, como se pode ver na notícia vinculada no site oficial dos empreendimentos em 07/11/2011.

Suape completa 33 anos e ganha obras de dragagem: Com a conclusão da dragagem, Suape estará habilitado a receber qualquer tipo de embarcação, inclusive, navios de minérios e os petroleiros que abastecerão a Refinaria Abreu e Lima a partir de 2013. "Suape não é mais um porto só dos pernambucanos, dos nordestinos ou dos brasileiros. Suape é um porto do mundo, estratégico para logística global e que vai ganhar mais relevo com a duplicação do canal do Panamá", destacou Eduardo Campos, atual governador de PE (SAMPAIO, 2011).

As consequências dessas ações são sentidas quando percebemos o desaparecimento de elementos que marcavam a territorialidade da Região. Dentre eles, salienta-se a descaracterização dos chamados "ranchos" dos pescadores. O rancho é o espaço onde os pescadores constroem suas territorialidades, uma rede infinita de significados da relação do homem com o mar. Guardam seus apetrechos, transmitem a sabedoria da pesca para as gerações mais jovens, suas técnicas, seus trabalhos, seus medos, suas brincadeiras, suas histórias e o respeito à natureza. Ou seja, é a vida cotidiana que é tecida todo dia neste 
ambiente (DIEGUES, 2007), que se tornam verdadeiros centros de vivência, onde, todos os dias, esses trabalhadores se reúnem, conversam, brincam, confeccionam suas redes, enquanto esperam a hora de voltar para o mar.

Na Região da Praia do Paiva existiam no mínimo dois ranchos em toda sua extensão. Um na Praia de Suape e outro na Praia do Paiva. O rancho da Praia de Suape foi destruído para a construção do Hotel Vila-Galé Eco Resort, e para a urbanização do local, com uma praça e lugar de convivência para os moradores e turistas.

O atual "rancho" dos pescadores da Praia de Suape está em péssimo estado de conservação. O local não tem uma estrutura básica necessária para atividade pesqueira, como uma balança para pesar o pescado, ou um isopor com gelo para a manutenção do pescado, antes da comercialização.

Já o "rancho" da Praia do Paiva, antes um palhoção, longe da maré para fixação das jangadas e balança para pesar o pescado antes da venda, hoje, se restringe a um espaço de terreno, delimitado pelos proprietários do local, a saber, a família Brennand.

As opiniões sobre a ação dos proprietários de reservarem um local para os pescadores na Praia do Paiva divergem em um primeiro momento, porém, ao analisar melhor, percebemos que, na essência, possuem o mesmo significado.

A fala do pescador R.V.A. (R12) quando afirma que o Complexo de Turismo e Lazer da Praia do Paiva influenciou significativamente a vida dos pescadores, a começar pela cerca colocada pelo empreendimento, limitando o "rancho" dos pescadores, é uma das perspectivas levantadas.

[...] Incomodou assim o acesso [...]. Como as coisas evoluiu. Tá entendendo, isso é um absurdo, essa cerca, o pescador tem 30 metros além da orla da praia. Aqui qualé a situação da gente aí. Até para colocar a jangada. Se a gente coloca mais pra cá, maré pequena a gente deixa aqui em baixo, para maré grande (R.V.A., R12).

Por outro lado, o pescador J.M.R.M. (R14), mais antigo, que se diz amigo do proprietário, tece o seguinte comentário sobre a área reservada para o "rancho":

[...] o dono daqui não quer que mexa com a gente aqui não, porque uma praia sem uma colônia, sem o peixe para ele comer, não é praia, tem que ter uma colônia de pescador para ele comprar o peixe, a lagostinha, ele compra sempre da gente, pra dá pros amigo dele (J.M.R.M., R14).

Percebe-se que o pescador acredita na "boa vontade" do proprietário, "o dono daqui não quer que mexa com a gente", porém, em seguida, apresenta, sem parecer estar consciente, 
o motivo da presença do "rancho", na localidade para os mesmos "[precisa ter] pescador para ele [o proprietário] comprar o peixe, a lagostinha, ele compra sempre da gente, pra dá pros amigo dele" (grifo nosso).

Outro elemento marcante da territorialidade do local que desapareceu em decorrências das ações dos quatro empreendimentos foi a Festa da Lavadeira. Celebração da cultura popular profana e religiosa da Região da Paiva do Paiva.

O evento acontecia, anualmente, no dia 01 de maio, desde 1987, no feriado do dia do trabalhador, e reunia uma média de 80 mil pessoas por edição, contagiando a todos com seu caráter religioso e ao mesmo tempo pagão e místico, assumindo, assim, um papel importante na territorialidade dos habitantes do local. O lado religioso da festa acontecia no dia 02 de maio, com oferendas para lemanjá (MELLO, 2011).

Em função dos interesses do Empreendimento Complexo de Turismo e Lazer da Praia do Paiva, seus proprietários conseguiram aprovar a lei municipal n. 9, de 11 de maio de 2010, que dispõe sobre o uso e gestão da orla, áreas verdes e institucionais e sobre a regra de trânsito e transporte na Zona Especial de Turismo e Lazer e Moradia na Reserva do Paiva (ZETLM). Dentre os vários aspectos pontuados pela lei, há um que determina a área, onde acontece a festa, como um espaço de lazer, turismo e moradia. Dessa forma, passa a ser proibida a realização de festas, montagem de palco, som e ônibus de turismo na praia. Ou seja, o poder político, beneficiando o poder do capital, vai aos poucos eliminando as territorialidades da Região da Praia do Paiva. A última versão da festa no local aconteceu em maio de 2011.

Essas ações geram relações sociais conflituosas, que remete a Lefebvre (1986 apud HAESBAERT, 2005), quando este afirma que tanto mais o território é funcionalizado, mais ele é dominado pelos agentes (hegemônicos) que o manipulam tornando-o unifuncional, portanto, menos propenso à apropriação pelos seus habitantes nativos.

Esse conflito é representado pela presença de dois agentes no mesmo território. De um lado, os moradores (dentre eles os pescadores artesanais) e os idealizadores da Festa, representados por Eduardo Mello, que lutam para manter a apropriação do espaço construída ao longo do tempo. Do outro, um grupo de empresários que, por meio da funcionalização do espaço, pretendem criar novas territorialidades para o local. As ações desses dois agentes caminham para lados opostos. 
Esses embates, rotina no território da Região da Praia do Paiva, são conhecidos apenas a partir das redes sociais, dos blogs, ou em sites direcionados à cultura popular, enquanto que as ações empreendidas pelos donos do capital estão sempre na mídia de massa e nos sites do governo, sinalizadas como fatores que vieram para melhorar as condições da comunidade nativa. As notícias veiculadas no site oficial do Complexo Industrial Portuário de Suape, destacando os resultados positivos de 2011, são exemplos disto:

O ano de 2011 foi positivo para o Complexo Industrial Portuário de Suape. A avaliação do ano mostrou um crescimento na movimentação de cargas e de contêineres no comparativo com 2010 [...].

Do mesmo modo, no site da Prefeitura do Cabo de Santo Agostinho é possível ler previsões de sucesso sobre o papel promissor do Complexo de Turismo e Lazer da Praia do Paiva.

O complexo turístico é interessante para o Cabo pelo papel alavancador que terá por meio da geração de empregos, renda e receitas tributárias, decorrentes de atividades econômicas que serão desenvolvidas, além do expressivo impacto social pelo treinamento profissional e capacitação de pessoas, contribuindo para o desenvolvimento da região (www.cabo.pe.gov.br - Acesso em: 22 dez. 2011).

[...] A geração de empregos também faz parte do programa de desenvolvimento para a região da localidade. O projeto da Reserva do Paiva, quando estiver em pleno funcionamento, deve gerar cerca de 38 mil empregos diretos e indiretos para as áreas de turismo e lazer, comércio e serviço, e condomínios residenciais. (www.orealizações.com.br/portal Acesso em: 22 dez. 2011)

\section{CONCLUSÕES}

[...] os lugares (territórios) se criam, e se recriam e se renovam a cada movimento da sociedade, e o motor desse movimento é a divisão [social] do trabalho, encarregada de, em cada cisão da totalidade transportar aos lugares [territórios], um novo conteúdo, mil novos significados, novos sentidos" (SANTOS, 2002, p. 14).

A noção de movimento apresentada por Santos nesta citação remete às transformações que estão ocorrendo na região da Praia do Paiva. Transformações estas que acompanham o constante movimento da sociedade, em função da evolução da ciência, da técnica e da informação, e, do território como algo que vai além de suas fronteiras físicas, materializado mediante seu uso, permitindo assim, a geração de conhecimentos e a construção de territorialidades (SANTOS, 2002).

Transformações territoriais que (re)organizam o espaço e intensificam a ocupação do solo e de seu uso, como um recurso a ser explorado, dando início a novos intercruzamentos de 
diferentes territórios, movidos por forças de fragmentação e desagregação da base territorial. Transformações geradas por ações políticas e econômicas provenientes de agentes sociais estranhos ao território, em função apenas das potencialidades do lugar, e da maximização de seus lucros, em detrimento da forma de viver dos seus antigos moradores.

As praias paradisíacas, o mar calmo, areia branca, sol praticamente o ano inteiro, a proximidade com a capital pernambucana foram os atrativos apresentados para justificar os investimentos de cunho turístico, imobiliário, e de lazer em toda a Região da Praia do Paiva. Sua posição geográfica estratégica, frente ao mercado europeu, e aos outros Estados nacionais, a potencialidade de calado do seu mar, e os incentivos fiscais concedidos pelo governo, por sua vez, justificaram os investimentos portuários na região.

Esses fatores, mais as contingências políticas e econômicas de trinta anos atrás, quando essas mudanças tiveram início, correspondiam à busca constante da mais valia desejada pelas empresas e deram início ao que Santos (2002) denomina "luta por lugares", quando afirma que "não é qualquer lugar que interessa a tal e qual firma" (p.68).

Dessa forma, empreendimentos de grande porte, que se instalaram na Região da Praia do Paiva, seja no ramo turístico, imobiliário ou industrial, passaram a estabelecer regras, em suas relações verticais e horizontais com os agentes envolvidos, induzindo e valorizando novas lógicas de trabalho, novos valores, e a geração de conflitos.

A materialização desses conflitos fica evidente na fala do pescador M.A. (R15) descrevendo esses novos operários como "invasores", na redução do pescado em decorrência das atividades dos novos agentes, nos aterros na ilha de Tatuoca, na redução do espaço dos "ranchos" dos pescadores da Praia do Paiva e na proibição, através de Lei Municipal, de uma manifestação da cultura popular da região, a Festa da Lavadeira.

Nesse contexto, nota-se que as relações, entre os antigos e novos habitantes do território da Região da Praia do Paiva, estão inseridas em um campo de poder e ligadas por uma dinâmica diária de interdependência entre todos os envolvidos. Relações estas que se hierarquizaram mediante ordens técnicas, financeiras e políticas, ditadas pelos agentes hegemônicos, que eram estranhos ao território e obedeciam às motivações distantes do mesmo (SANTOS, 2002).

A agressão ao meio ambiente, o aterro permitindo o acesso de carro às ilhas de Cocaia e Tatuoca, a redução da atividade pesqueira artesanal das marisqueiras (por conta das obras de terraplanagem), a não continuidade da Festa da Lavadeira no local, o deslocamento de 
um dos símbolos da territorialidade dos pescadores artesanais (seu "rancho") para uma área restrita, em função dos interesses particulares de seus proprietários, foram algumas das consequências da instalação desses empreendimentos na região.

As evidências geradas mostram que as transformações na Região da Praia do Paiva são pontuadas por vantagens marcante para o capital econômico, o que nos levam a duvidar da possibilidade sugerida por Santos (2001) para um território: a construção de uma história das ações que seja diferente do projeto dos atores hegemônicos (SANTOS, 1996).

As transformações territoriais aqui descritas estimulam a atividade intelectual para outros estudos, não só na expectativa de encontrar resistências a este movimento hegemonizador, mas também para revelar os efeitos negativos que estes tipos de ações trazem para os mais fracos economicamente.

Nesse sentido, essa pesquisa contribui no sentido de ampliar (incluir, na verdade) os interesses não só econômicos, mas, e sobretudo, a preocupação com os efeitos deste capital sobre as comunidades nativas (oprimidas). É o poder de denúncia que justifica este trabalho. Ao final, embora sinais tenham sido apontados, percebemos que as novas formatações econômicas, políticas e culturais do novo território ainda estão a configurar na Região da Praia do Paiva, mesmo que alguns dos seus sinais transfiguradores já tenham surgido.

\section{REFERÊNCIAS BIBLIOGRÁFICAS}

ALBERTI, V. Manual de história oral. Rio de Janeiro. Fundação Getúlio Vargas. 2011.

ARAUJO, M. A.; BELO, P. deS. Grandes projetos minerários e comunidades tradicionais na Amazônia: impactos e perspectivas. Revista Política Pública. São Luis, v. 13, n. 2, jul./dez. 2009 , p. $265-277$

CORIOLANO, L.N.M.T. Turismo: prática social de apropriação e de dominação de territórios. América Latina: cidade, campo e turismo. Amalia Inés Geraiges de Lemos, Mónica Arroyo, Maria Laura Silveira. CLACSO, Consejo Latinoamericano de Ciencias Sociales, San Pablo, dezembro, 2006.

DIEGUES, A.C.S. Pesca e marginalização no litoral paulista. Dissertação de Mestrado. NUPAUB./CEMAR, USP, São Paulo, 1973, 187 p. 
FERNANDES, D. Território e territorialidade: algumas contribuições de Raffestin. Perspectiva e Políticas Públicas. Belo Horizonte, v.2, n.4 p.59-68, jul/dez, 2009.

FLICK, Uwe. Uma introdução à pesquisa qualitativa. 2 ed. Porto Alegre: Bookman, 2004.

GOLDENBERG, M. A arte de pesquisar: como fazer pesquisa qualitativa em Ciências Sociais. Rio de Janeiro: Ed. Record, 2000, p. 36.

GOULART, S. et al. Articulações em rede e acontecimentos no território: subsídios teóricos para a formação de políticas públicas para o desenvolvimento. Cadernos EBAPE. BR, v. 8, no 3, artigo 1, Rio de Janeiro, p. 388-403, set. 2010

HAESBAERT, R. O mito da desterritorialização: do fim dos territórios à multiterritorialidade. Rio de Janeiro. Bertrand. Brasil. 2004.

HAESBAERT, R. Da desterritorialização à multiterritorialidade. X Encontro de Geográfos da América Latina. Anais...São Paulo 20 a 26 de março de 2005 . Universidade de São Paulo,p. 6774-6792.

LITTLE, P.E. Territórios sociais e povos tradicionais no Brasil: por uma antropologia da territorialidade. Série antropológica. Universidade de Brasília, Brasília, 2002

MARCONI, M. de A.; LAKATOS, E.M. Técnicas de pesquisa. 4ed. São Paulo: Atlas, 1999.

MELLO, Eduardo. Noticias. Disponível em: <www.festadalavadeira.com.br>. Acesso em: 12 dez. 2011.

MERRIAM, S.B. Qualitative research and case study applications in education. 2 ed. San Francisco, CA, Jossey-Bass, 1998.

PESSOA, L.C.R; BOGUS, L.M.M. Valorização Imobiliária e renovação urbana: o caso das Operações Urbanas Consorciadas Faria Lima e Água Espraiada. Caderno Metrópole, v.20. 2008.

RAFFESTIN, C. Por uma geografia do poder. Maria Cecília França. (trad.), São Paulo, Ática, 1993. 
RAMALHO, C.W.N. Embarcadiços do encantamento: trabalho com arte, estética e liberdade, na pesca artesanal de SUAPE, PE.2007. 301 f.Dissertação (Doutorado em Ciências Sociais),UNICAMP, Campinas,2007.

SAMPAIO, Marcella. Núcleo de Comunicação de Suape: Notícias. Disponível em:

<www.suape.gov.pe.br>. Acesso em: 18 set. 2011

SANTOS, M. Por uma geografia nova: da critica da geografia a uma geográfica crítica. 3o. São Paulo: HUCITEC, 1996.

SANTOS, Milton. Guerra dos lugares. Entrevista Folha on line, 8/8/1999. Disponível em <http://www1.folha.uol.com.br/fol/brasil500/dc_3_5.htm.> Acesso em: 27 nov. 2010.

SANTOS, Milton. A natureza do espaço. São Paulo, Editora Universidade de São Paulo, 2002.

SANTOS, Milton. Por uma outra globalização: do pensamento único a consciência universal. 6 ed. Rio de Janeiro, Record, 2001.

SANTOS, M,; SILVEIRA, M.L. O Brasil: território e sociedade no início do século XXI. Rio de Janeiro, Record. 2008.

SIMÕES. H.C.G.Q. A história e os efeitos sociais da mineração no Estado do Amapá. Revista Eletrônica de Humanidades do Curso de Ciências Sociais da UNIFAP, Amapá, n. 2 p.1-14. dezembro, 2009.

SOUZA NETO, et al. A modernização do litoral cearense e as comunidades pesqueiras: o caso de Tatajuba, Camocim-Ce. In: Seminário Internacional de Turismo Sustentável, 2., 2008, Fortaleza. Anais... Fortaleza. 2008.

THOMPSON, P. A voz do passado. História Oral. 3 ed. Rio de Janeiro, Paz e Terra, 2002.

TRIVINOS, Augusto Nibaldo Silva. Introdução à pesquisa em ciências sociais: a pesquisa qualitativa: o positivismo, a fenomenologia, o marxismo. São Paulo: Atlas, 1987.

Artigo recebido em 11/03/2013.

Artigo aceito em 10/04/2013. 